\title{
Historikern, experterna och steriliseringarna av resanderomer
}

\author{
Maija Runcis
}

Sverige har en mörk historia när det gäller behandlingen av romer och resande. Den första delen av I900-talet handlade om ren rasideologi som i sin yttersta form gick ut på att romer inte borde leva i Sverige. Romska mödrar fick inte ta del av mödrahälsovård och sterilisering användes för att de romska generna inte skulle föras vidare. Under andra delen av I900-talet suddades rasideologin sakta bort och ersattes av välfärdssamhällets kartläggningar och övervakning. ${ }^{\mathrm{I}}$

Detta citat är hämtat ur regeringens vitbok Den mörka och okända historien - Vitbok om övergrepp och kränkningar av romer under I900-talet. Det är dåvarande integrationsministern Erik Ullenhag som $\mathrm{i}$ inledningen till boken yttrar sig om det svenska samhällets behandling av romer och resande. Vitboken kom till i syfte att sprida kunskap om hur romerna i Sverige behandlats under I900-talet. Tanken var att historien skulle kunna förklara romernas villkor i Sverige idag. Därigenom ville regeringen stärka arbetet med romers mänskliga rättigheter samt förbättra romers levnadsförhållanden. Vitbokens historieskrivning bygger till stor del på de berördas egna upplevelser och gruppens kollektiva minnesarbete.

Det finns också många andra vittnesmål om övergrepp mot romer och de senaste två decennierna har statliga utredningar om etnisk och social diskriminering av romer avlöst varandra. ${ }^{2}$ Det står klart att till skillnad från tidigare myndighetsexperter delar dagens experter Vitbokens bild av en historia full av övergrepp från samhällets sida. I den här artikeln kommer jag att påbörja

Hur du refererar till det här kapitlet:

Runcis, M. 20I6. Historikern, experterna och steriliseringarna av resanderomer. I: Sandén, A. \& Elgán, E. (red.) Kunskapens tider: Historiska perspektiv på kunskapssambället. Pp. I IO-I 27. Stockholm: Stockholm University Press. DOI: http://dx.doi.org/IO.I6993/bai.h. License: CC-BY 4.0 
en granskning av steriliseringar av vissa av de grupper som i dag räknas in i den romska minoriteten.

\section{Den romska minoriteten i Sverige}

I999 erkändes romer som en av fem nationella minoriteter i Sverige. Den nationella minoriteten romer består i sin tur av fem grupper: Svenska romer, finska romer, utomnordiska romer, nyanlända romer och resandefolket. Resanderomer eller resandefolket, som under I900-talets första hälft av myndigheterna benämndes "tattare", har funnits i Sverige sedan flera århundraden och utgör idag den största gruppen inom den romska minoriteten. ${ }^{3}$ Fram till mitten av I950-talet gjorde såväl vetenskapen som myndigheterna skillnad mellan "tattare" och "zigenare" även om de båda grupperna betraktades som socialt problematiska. Det fanns en föreställning om att "tattarna" ursprungligen var en blandning mellan "zigenare" och "svenskar" medan "zigenarna" saknade "svenskt blod". Den sistnämnda gruppen är ättlingar till de åtta romska familjer som kom till Sverige från Rumänien i slutet av I 800-talet. ${ }^{4}$ "Zigenarna" hade under flera decennier därefter inreseförbud till Sverige. ${ }^{5}$

Benämningarna "tattare" och "zigenare" anses idag stigmatiserande och de nya officiella beteckningarna "resande" och "romer" illustrerar ett nytt förhållningssätt från myndigheterna gentemot dessa grupper. ${ }^{6}$ I regeringens vitbok har resande och romer behandlats som en enhetlig kategori även om båda benämningarna förekommer.

Användningen av de skilda beteckningarna visar hur resande och romer har skapats som sociala och kulturella kategorier i olika sociala sammanhang och/eller maktförhållanden samt hur dessa har förändrats över tid. Allt sedan sekelskiftet I900 har vetenskapsmän, läkare, politiker, präster och övriga myndighetsrepresentanter bidragit till stereotypiseringen av romer. Även vi samtida forskare har bidragit till en fortsatt stereotypisering då vi har fört vidare dåtidens benämningar och pejorativa uttryck hämtade ur de historiska källorna. Ekonomhistorikern Paulina de los Reyes menar till exempel att "forskning som har bedrivits om steriliseringslagstiftningen i Sverige har bidragit till att skapa en 
missvisande bild av steriliseringspolitikens omfattning och konsekvenser för romer". 7 Eftersom jag tillhör dem som har forskat om steriliseringar i Sverige på I900-talet tar jag kritiken på allvar. Det vi historiker har förbigått, enligt de los Reyes, är de samlade erfarenheterna av sterilisering och förföljelser som är ett återkommande tema i de berättelser som berättats av romer och resande, men även av journalister de senaste decennierna. ${ }^{8}$ de los Reyes menar dock att kvalitativa studier som t.ex. diskursanalyser skulle ge andra resultat än de kvantitativa studier som hon menar har dominerat forskningen om steriliseringarna.

Jag instämmer i att kategorin "tattare", som den beskrivs i utredningar och politiska debatter från I900-talets första hälft, överensstämmer väl med många av de uttryck och markörer som förekommer i steriliseringsansökningarna där enskilda individer steriliserats på eugenisk eller social indikation. Jag håller också med om att det finns direkta utpekanden av "tattare" - dock inte av "zigenare" - i den politiska och medicinska diskursen om steriliseringslagarnas tillämpning. Men till skillnad från de los Reyes anser jag inte att detta räcker som belägg för att säga att de personer som steriliserades med hänvisning till sociala missförhållanden och "asocialt levnadssätt" under I930- till I950-talets var "tattare".

Under alla förhållanden kan vi konstatera att det bland forskare som studerat steriliseringsfrågan råder skilda ståndpunkter: den kvantitativa som menar att resanderomer är en marginell kategori bland de steriliserade medan den kvalitativa anser att romer måste betraktas som överrepresenterade i steriliseringsstatistiken, eftersom vi "[m]ed kunskap om dåtidens resonemang om tattarnas egenskaper är [...] så nära man kan komma ett utpekande av gruppen som särskilt lämplig för en steriliseringslag." 9 Regeringens vitbok från 20I4 är inne på samma linje då den framhåller att det råder en diskrepans mellan romernas "kollektiva minnen av steriliseringar och deras perifera position i sterili-

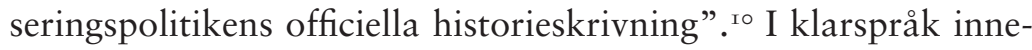
bär detta att romernas minnen av övergrepp inte överensstämmer med den statliga utredning som genomfördes på I990-talet och som bland annat gick igenom vilka som blev föremål för steriliseringsingrepp. 
Min avsikt i denna artikel är inte att förringa romernas erfarenheter av förföljelser och övergrepp. Jag vill heller inte polemisera mot, eller förneka andra forskares studier av den svenska steriliseringspolitiken, vare sig det gäller politiska diskurser eller praktiker. Jag vidhåller dock att det är problematiskt att säga att eftersom expertspråket i steriliseringsakterna innehåller samma typer av nedsättande termer som dem som användes om romer, betyder det inte att alla som steriliserades var romer, utan där fanns också andra socialt stigmatiserade grupper. Min avsikt i denna artikel är att ställa olika delar av dåtidens expertkunskap mot varandra. Detta görs genom att Socialstyrelsens s.k. tattarinventering granskas i relation till Medicinalstyrelsens steriliseringsakter, för att se om det med hjälp av de mer traditionella historiska metoderna som källkritik går att komma längre i fastställandet av hur stor del av de steriliserade som var resanderomer.

\section{Berättelser om romer ur ett ovanifrånperspektiv}

Men hur såg berättelserna om resanderomer ut på I930-50 talen? Vilka var "berättarna" och vad representerar berättelserna? Jag menar att detta är viktigt att studera, eftersom en stor del av berättelserna har präglat romerna och deras förhållande till myndigheterna och samhället i stort. ${ }^{\text {I }}$ Det är också viktigt att få en bild av samtidens syn på romer för att se om dessa lägger grunden för steriliseringslagens praktik under denna period.

Den 25 september 1942 fick socialstyrelsen regeringens uppdrag att "verkställa inventering av de tattare och zigenare, som finnas inom riket". Syftet med inventeringen var:

att ge kännedom om ifrågavarande befolkningsgruppers storlek och spridning inom landet och hade föranletts av vissa framställningar till Kungl. Maj:t om utredning angående de sociala problem, som tattarna till följd av sitt levnadssätt och olägenheterna, därav för den övriga befolkningen givit upphov till på en del orter. Ehuru i fråga om zigenarna några klagomål icke anförts beträffande deras förhållande till andra samhällsmedlemmar, ansågs det lämpligt att i detta sammanhang även undersöka zigenarbefolkningens storlek. Vid socialstyrelsens planläggning av den anbefall- 
da inventeringen ha av olika skäl särskilda undersökningar ansetts böra verkställas för tattare och zigenare. ${ }^{\text {I2 }}$

Socialstyrelsen beslutade således att utföra två skilda inventeringar, eftersom man ansåg att "tattare" och zigenare" var två skilda folkgrupper. Socialstyrelsens experter konstaterade också att ur social synpunkt hade "den svårutredda frågan om tattarnas ursprung endast sekundär betydelse". ${ }^{\mathrm{I}}$ I samband med initieringen av denna nya "tattarinventering" (tidigare inventeringar hade gjorts I922-23) inhämtades däremot kunskap om "tattare" både från folklivsforskare och från Rasbiologiska institutet. Dessa rapporter skiljer sig åt $\mathrm{i}$ fråga om beskrivningen av "tattare" och resandefolkets egenskaper. Rasbiologiska institutets rapport utgör en antropologisk undersökning av "tattare" och har en vetenskaplig karaktär, till skillnad från den etnologiska undersökningen gjord av Nordiska museets upptecknare. I den senare speglas en dåtida folklig diskurs om resandefolket, som till exempel i det följande citatet. Uppteckningen är gjord av Karl G Larsson, Måljem Nol, i Bohuslän, I 943 och utgör en del av Socialstyrelsens "tattarinventering" I943:

Allmogen brukade uppdela det kringflackande vandringsfolket i tvenne grupper, nämligen tattare och zigenare. Zigenarna voro hållna för att vara renrasiga folkelement ifrån sydöstra Europa, väl förtrogna med Troll- och spådom samt $\mathrm{i}$ besittning av ansenlig förmögenhet ofta i form av kedjor och smycken, som buros av såväl män som kvinnor.

Zigenarna klädde sig bättre än tattarna och hade sig sinsemellan sitt eget språk. Zigenarstammen hade även hövding, vilken till tecken på sin värdighet bar stav. Stammens medlemmar måste absolut lyda hövdingen. Svenska språket talade zigenarna mycket dåligt varför de ofta brukade teckna då de önskade sig något.

Tattarna anses däremot utgöra en blandning av allt slags "pack" (sämre folkelement) såsom fördrivna zigenare, valloner, svenskt slödder och finnar vilka genom inavel och fattigdom utgjort och utgöra alltfortfarande en samling snuskiga individer, livnärande sig på andra människors enfald och godtrogenhet eller och övande tjuveri, bedrägeri, tiggeri och rån. ${ }^{\mathrm{I} 4}$

Citatet speglar tydligt vilka personer uppgiftslämnaren anser utgör "den andre", de som inte passar in hos "oss", som avviker från 
övriga individer i det svenska samhället. Intressant att notera är att här liksom i anvisningarna till Socialstyrelsen dras en skarp linje mellan kategorin "zigenare" som sägs vara ett främmande "renrasigt" folk från en annan tid, medan "tattarna" beskrivs som ett "sämre folkelement" och ett samtida samhällsproblem. Detta synsätt skiljer sig ju markant från dagens uppfattning där dåtidens "tattare" och "zigenare" numera förs till en enhetlig kategori, romer. Uppteckningarna från Nordiska museet visar att det vid den här tiden fanns en rasbiologisk diskurs hos svenska folket. Denna saknar dock den vetenskapliga karaktären som blir tydlig i Rasbiologiska institutets rapport, som sammanställts av professorn och tillika chefen för Statens Rasbiologiska institut, Gunnar Dahlberg. Även Dahlberg gör en åtskillnad mellan "zigenare" och "tattare" där den senare gruppen betecknas som "vagabonderande" och har i "viss mån asocial livsföring" medan "zigenarna" skilde sig i "klädedräkt, språk etc." från den svenska befolkningen. ${ }^{\text {I }}$ " Zigenarna” ansågs ha en främmande etnisk härkomst och de betraktades inte som svenskar på samma sätt som kategorin "tattare":

Inledningsvis må framhållas, att bland personer, som ha rent svensk härstamning, måste finnas åtskilliga, som utmärka sig för den livsföring, som angivits i det föregående. Det finns också personer, vilka ha rent svensk härstamning och det oaktat äro mörklagda. Det bör under sådana omständigheter ej möta större svårigheter att finna svenskar, som i avseende på såväl livsföring som utseende överensstämma med de föreställningar man förbinder med ordet tattare. ${ }^{16}$

Dahlberg kunde vidare konstatera att det bland den undersökta kategorin "tattare" inte heller förelåg någon "rasmässig avvikelse" i fråga om kroppsbyggnad. Däremot uppvisade "tattarna" mindre axelbredd och mindre huvudmått med kortare ansikten. Undersökningen kunde säkerställa "skillnader såväl för pannans som huvudets bredd samt också för huvudets längd". Detta ansågs vara ett uttryck för "en mindre utvecklad hjärnskål hos tattarna och det ligger nära till hands att misstänka, att tattarna också ha något mindre hjärna än vad som utmärker svenska folket i genomsnitt.” ${ }^{17}$ Så talade chefen för rasbiologiska institutet I944, men han avslutade sin rapport med att konstatera att det inte på ett objektivt sätt gick att skilja ut "tattare" från andra svenska medborgare. ${ }^{18}$ 


\section{De svenska steriliseringslagarna}

I min avhandling Steriliseringar i folkhemmet, valde jag att studera steriliseringslagarnas tillämpning utifrån ett genusperspektiv. Jag ställde mig frågan hur det kom sig att $93 \%$ av de steriliserade individerna var kvinnor, när lagarnas tillämpningsområde gällde "vissa sinnessjuka, sinnesslöa eller andra som lida av rubbad själsverksamhet". Ansågs kvinnor vara mer utsatta för "sinnesslöhet" eller själslig "rubbning” än män? Svaret blev, kanske något förvånande, nej! Den samtida medicinska sakkunskapen visade att förhållandet var helt tvärtom, dvs. "sinnesslöhet" och sinnessjukdom hade bekräftats vara vanligare hos män. Alltså måste andra argument sökas för att finna förklaringar till kvinnors överrepresentation i materialet.

Ett skäl till att kvinnor hamnade i fokus för lagens praktik var bl.a. den sociala indikationen för sterilisering, dvs. då individen ansågs vara ur stånd, eller uppenbart olämplig att ha hand om vårdnaden om ett barn. Denna indikation fanns med i både 1935 och I94 I års steriliseringslagar. En lagändring I94 I breddade lagens tillämpning med tillägg av indikationerna "asocialt levnadssätt" samt medicinsk indikation, där den sistnämnda endast kom att gälla s.k. "utsläpade mödrar" och kvinnor som på grund av fysisk och psykisk "svaghet" riskerade sin hälsa i samband med graviditeter. I fråga om steriliseringar på social indikation avtecknade sig ett tydligt könsmönster som även följde lagens tillämpning, där s.k. ohämmad sexualitet så gott som alltid förknippades med “olämpliga mödrar” eller "asociala” kvinnor, som födde barn utom äktenskapet. Genom denna blandindikation (social och medicinsk) som omfattade kvinnors sexualitet och barnafödande ansåg experterna att de värnade utsatta barn samt utsatta kvinnor med många barn. Lagstiftarna talade om barnrika familjer i svåra ekonomiska och sociala situationer, till exempel där hustrun var utsläpad av många barnsbörder och mannen socialt "undermålig” eller alkoholiserad. I dessa situationer där familjens välfärd ytterligare kunde "hotas" genom nya graviditeter skulle sterilisering av kvinnan vara väl motiverad, eftersom preventivmedel kunde innebära en alltför osäker rekommendation. ${ }^{19}$ De sakkunniga resonerade även kring möjligheterna att sterilisera den "asociale" mannen, men experterna trodde att det skulle vara svårare att 
erhålla mannens samtycke för sterilisering även om denne bedömdes vara psykiskt abnorm. Det påpekades dock att i samtliga fall där blandindikationer av "humanitär”, ekonomisk, social och rashygienisk grund förelåg, skulle en i familjen steriliseras. Om den ene vägrade skulle den andre steriliseras. ${ }^{\circ} \mathrm{I}$ denna diskussion smög sig ett tydligt könsmönster in i utredarnas argumentation då det förutsattes att kvinnan skulle vara mer medgörlig eller mer underdånig inför myndigheternas eller läkarens påtryckning. ${ }^{2 r}$ Därigenom befästes bilden av kvinnan som det svagare könet och den som samhället kunde kontrollera.

Ansökningar om sterilisering kunde göras av fattigvårdsnämnder, barnavårdsnämnder och andra myndighetspersoner. Vanligast förekommande bland de som ansökte om sterilisering för kvinnornas del under I930-I950-talet var fattigvårdsnämnden och barnavårdsnämnden. För männens del var det mestadels anstaltspersonal som ansökte om sterilisering i samband med utskrivning från anstalten.

Huvudsyftet med I94I års lag var att uppnå större effektivitet i tillämpningen genom att reglera alla former av steriliseringsingrepp. Kriterierna för "tattare" kunde mycket väl passa in i indikationen "asocialt levnadssätt" utifrån de rådande beskrivningarna och berättelserna, men de kvinnor som steriliserades på grund av "asocialt levnadssätt" betraktades i regel som "sexuellt hållningslösa" - en markör som inte är vanligt förekommande i "tattardiskursen". En genusanalys av steriliseringsakterna visar att kvinnor pekades ut på sociala och moraliska grunder i en "folklig diskurs", t.ex. av grannar, anhöriga, folkskollärare eller fattigvårds- och barnavårdsnämnder, medan männen dömdes för brott mot lagar, t.ex. stölder, ekonomisk försumlighet, våld och missbruk, och bestraffades på juridiska grunder. Männen steriliserades främst i samband med utskrivning från anstalter. ${ }^{22}$

Den vetenskapliga rasbiologin och dess tillämpade form, rashygienen, gjorde anspråk på kunskaper om såväl psykiska som moraliska egenskaper hos individer. Rasbiologerna klassificerade individer efter yttre skiljelinjer. Etniska och kulturella egenskaper betraktades som nedärvda och ärftliga. ${ }^{23}$ I diskussionerna till I94 I års steriliseringslag om vilka som skulle omfattas av den nya lagen kan man tydligt se hur det medicinska vetenskapsfältet gavs 
ett både rasbiologiskt och moraliskt innehåll. Det "omoraliska" och "asociala” levnadssättet medikaliserades och gjordes ärftligt. Detta avspeglas framför allt i frågan om vilka individer och sjukdomsbegrepp som skulle inbegripas i lagens tillämpningsområde. Utredarna talade om "gränsfallen”, d.v.s. sådana fall som var svåra att ta ställning till beträffande sjukdomsbild och rättskapacitet, och som ansågs kunna bli ett problem i lagens tillämpning. "Tattarna" nämns inte explicit i lagens förarbeten, däremot kom flera av kriterierna för sterilisering att vara desamma som dem som vi sett användes några år senare för att beskriva resanderomerna.

Ur "praktisk synpunkt" ansågs asociala egenskaper utgöra en stabil grund för sterilisering, vid bedömning av enskilda fall. "Undermålighet" kunde yttra sig både på det intellektuella och det moraliska planet, menade experterna. De "höggradigt asociala" kunde även karakteriseras som "svårartade psykopater". Denna grupp bedömdes vara mycket stor och omfattade en del yngre "vanartiga" individer som fanns både innanför och utanför skydds- och uppfostringsanstalterna. Bland dem som kallades för debila och psykopater ingick också vissa "arbetsskygga” individer, till exempel prostituerade och vagabonder. ${ }^{24}$ Dessa grupper borde, enligt de sakkunniga, steriliseras i största möjliga utsträckning och för samhällets bästa, eftersom de förorsakade stat och kommuner stora ekonomiska utgifter. ${ }^{25}$ De sakkunniga gick som katten kring het gröt vad gällde benämningen "tattare", vilket medförde att kategorin i steriliseringslagens praktik inte pekades ut som en särskild ras, utan i förekommande fall steriliserades på grund av "vagabonderings-tendenser" eller "asocialt levnadssätt”. Denna tvehågsenhet visar tydligt att experterna inte var överens om hur kategorin "tattare" skulle definieras och identifieras och därför kom de att inkluderas i den allmänna kategorin misskötsamma och "asociala" individer. Det är i ytterst få steriliseringsansökningar som benämningen "tattare" anges och efter I955 försvann begreppet helt i steriliseringsansökningarna.

\section{Socialstyrelsens "tattarinventering" 1943}

Mot bakgrund av Vitbokens uppgifter om att majoriteten resanderomer har erfarenheter av övergrepp och steriliseringar från 
myndigheternas sida är det intressant att studera denna fråga djupare än vad jag tidigare har gjort. För att se om resanderomer särskilt pekats ut i steriliseringsakterna har jag valt att jämföra Socialstyrelsens "tattarinventering" I 943 med ansökningar om sterilisering till Medicinal- och Socialstyrelsens rättspsykiatriska nämnd. "Tattarinventeringen" utfördes under åren 1943-44 och bestod av en kartläggning av 7668 "tattare”, fördelade på I 947 hushåll i 436 kommuner. ${ }^{26}$ Inventeringsuppgifterna omfattar de registrerades födelsedata, födelseort, bostadsort, civilstånd, sysselsättning m.m. Även personer tillhörande samma bostadshushåll redovisas. På registerkortet anges också skälen för att personen/ hushållet registrerats som "tattare", t.ex. deras levnadssätt samt huruvida de använder sig av det s.k. "tattarspråket".

Kartläggningen utfördes av särskilda sagesmän såsom präster, lärare, kommunala förtroendemän och funktionärer samt enskilda, som ansågs förtrogna med ortstraditionerna. "Polismyndigheterna behövde däremot icke låta uppsöka och utfråga de personer, som skulle redovisas såsom tattare", enligt Socialstyrelsens sakkunniga. Det betonades i direktiven att inventeringen skulle omfatta samtliga resande, dvs. både skötsamma och icke skötsamma "asociala element" ${ }^{27}$

Min undersökning utgår från en jämförelse mellan dessa registerkort och diarier till steriliseringsansökningarna. Det totala antalet steriliserade uppgår till 63 ooo för perioden I935-I975. Jag har valt perioden I935 till I957 som jämförelsegrund för min undersökning. Valet av undersökningsperiod grundar sig på att det fram till 1957 finns alfabetiska register i steriliseringsdiarierna som möjliggör en jämförelse, samt också att "tattare" upphör som begrepp i offentliga utredningar efter I955. Undersökningen baseras helt på arkivhandlingar där de enskilda individernas egna röster inte kommer till tals, men där de ändå finns synliga med alla sina personuppgifter, familjemedlemmar och beskrivningar av sociala förhållanden.

\section{Tattaren är en man}

Med mitt bidrag vill jag dels fördjupa genusperspektivet och dels problematisera bilden av steriliseringar av resanderomer, bl.a. för 
att söka svar på om "tattare" var särskilt utpekade i steriliseringslagens praktik. Jag har valt ut ett antal län från "tattarinventeringen" (Stockholms län, Göteborgs- och Bohuslän, Älvsborgs län, Gävleborgs län samt Skaraborgs län) som totalt omfattar 595 hushåll ( I registerkort/hushåll).

En översiktlig genomgång av inventeringen ger vid handen att majoriteten av de registrerade personerna var män. Endast I 24 registerkort av de 595 (2I \%) registrerade hushållen gällde kvinnor. Socialstyrelsen reflekterade själv över att andelen kvinnor var låg $\mathrm{i}$ förhållande till registrerade män, viket enligt styrelsen kunde bero på "att en del kvinnor av tattarbörd, vilka genom gifte eller av andra skäl lämnat tattarmiljön, ej kommit med i materialet. /.../ Av naturliga skäl tilltalas kvinnor högst sällan av ett vagabonderande liv; kvinnliga luffare är ju - utanför zigenarnas och tattarnas krets - ett nästan okänt begrepp". ${ }^{28}$

För att avgränsa arbetet till en rimlig proportion valde jag Göteborgs och Bohuslän för närmare analys. I detta län registrerades totalt 276 "tattarhushåll" varav 50 kvinnor stod för hushållet, (lite drygt I $8 \%$ ).29 De manliga "tattarhushållen" bestod av I6I gifta "tattare" där majoriteten hade hustrur som även de ingick i samma kategori. Endast 40 män var gifta med kvinnor som inte kategoriserats som "tattare" och där detta även noterats i registerkortet. Eftersom en överväldigande majoritet av dem som steriliserades var kvinnor har jag koncentrerat min undersökning på de 50 hushållen som registrerats på kvinnorna och deras familjer som alla bodde i Göteborg eller i Bohuslän. Undersökningen har gjorts genom att jämföra kvinnornas (och i förekommande fall även deras familjers) personuppgifter med Medicinalstyrelsens och Socialstyrelsens diarier över inkomna steriliserings-ansökningar för åren I935-I957. Att gå igenom diarierna på detta vis var en grannlaga uppgift som gav magert resultat. Detta kan delvis förklaras med att 25 av kvinnorna var i pensionsåldern. För att kompensera för detta granskade jag även om andra i familjen och de vuxna barnen förekom i steriliseringsansökningarna.

Jag fann faktiskt endast en kvinna från "tattarinventeringen" i steriliseringsdiarierna. Det var en kvinna som vid 35 års ålder I94 I steriliserades i samband med utskrivning från en alkoholistanstalt. Hon hade ett halvår innan steriliseringen fött 
sitt fjärde barn som togs ifrån henne direkt efter födseln och placerades på barnhem. Två av hennes yngsta pojkar var sedan tidigare placerade på barnhem. Kvinnan var gift med en man, en renhållningsarbetare, som inte kategoriserats som "tattare" vare sig i Socialstyrelsens "tattarinventering" eller i kvinnans steriliseringsansökan.

Kvinnans fall reflekterar väl den svenska steriliseringsdebatten från I930- och 40-talets början som innehåller både arvshygieniska och moraliska argument. Det talades i flera sammanhang om betydelsen av att sterilisera alkoholister, psykopater, lösdrivare, "tattare", vagabonder och andra asociala typer, eftersom deras läggning i grunden sades bero på själslig rubbning. Hennes akt i “tattarinventeringen" speglar också hur myndigheterna genom att anlita lokala experter skaffade sig kunskap om gruppen resanderomer. Uppgifterna i "tattarinventeringen" om kvinnans liv och leverne hade lämnats av förre folkskolläraren Carl Hillström i Mölndal samt hälsovårdsinspektören Gerle Jönsson. Orsaken till att kvinnan registrerades i "tattarregistret" var enligt uppgifterna på registerkortet: "hävdvunnen uppfattning om kvinnan samt rasdrag, och levnadssätt". ${ }^{\circ}$

Av de 50 registrerade kvinnliga hushållen i Göteborgs och Bohus län i 1943 års "tattarinventering" hade i hälften (25 registerkort) av fallen uppgifterna lämnats av polisen, som ansågs ha god kännedom om lokalbefolkningen. Polisen fick dock inte uppsöka enskilda individer för att registrera dem (se ovan) utan detta skulle ske med allmänhetens medverkan och polisens egen erfarenhet. I I 8 fall hade uppgifter lämnats av Barnavårdsnämnden eller Fattigvården. I 9 fall hade uppgifterna inkommit från en och samma person, nämligen sysslomannen i Uddevalla. ${ }^{3 \mathrm{I}}$ Dessa kvinnor ansågs som skötsamma i bygden men bedömdes som "tattare" av "hävdvunnen uppfattning".32

Så här långt kan vi sammanfatta undersökningen om steriliseringar av resanderomer i Göteborg och Bohuslän under perioden I935-I957 med att endast en av de personer som står upptagna i den så kallade tattarinventeringen står att finna i registret över steriliseringsakter. Sammanfattningsvis har min lilla undersökning gett resultatet att majoriteten av de som registrerades i Socialstyrelsens "tattarinventering" I943 var män. 
Kvinnorna fanns förvisso där men då som familjemedlemmar (vuxna barn, hustrur varav många noterats som "ej av tattarsläkt”). I vilken mån kvinnorna som gift in sig i resandekulturen och eventuellt blivit steriliserade har inte undersökts. Här krävs ytterligare undersökningar ( I6I registerkort) för att säkerställa resultat. Med reservation för tolkningar av materialet törs jag ändå påstå att det inte går att hävda att resanderomer skulle vara en överrepresenterad grupp bland de steriliserade. Denna tolkning grundar jag på att majoriteten av de som steriliserades var kvinnor, medan Socialstyrelsens inventering domineras av män. Därmed bekräftas de forskningsresultat som jag, och senare även Mattias Tydén har kommit fram till i våra respektive avhandlingar.

De kvinnor som steriliserades på social indikation eller på grund av "asocialt levnadssätt" ansågs ligga samhället till last genom att de saknade egen försörjning och därmed inte kunde ta hand om de egna barnen. De steriliserade kvinnorna fick alltså bära ett personligt ansvar för den bristande sociala miljö som de levde i. Det var för det mesta i samband med att kvinnorna kom i kontakt med myndighetsrepresentanter från barnavården, fattigvården eller sjukvården som steriliseringsprocessen inleddes. Dessa kvinnor saknade de "vagabonderingstendenser" som ju ansågs känneteckna resandefolket och som var en förutsättning för resandefolkets försörjningsmöjligheter. Resandet utgjorde en möjlig grund för försörjning av allehanda slag, även om detta skedde mestadels under den varmare säsongen på året. Dessutom gjorde resandefolket allt för att undvika, det som av folket självt uppfattades som myndigheternas repressiva åtgärder. Att gömma sig för de sociala myndigheterna blev helt enkelt en överlevnadsstrategi, eftersom resande inte själva fick definiera det egna hjälpbehovet. ${ }^{33}$ På denna punkt hade myndigheterna ensamma problemformuleringsprivilegiet. Att resanderomer diskuterades flitigt i steriliseringsdiskursen är ett tydligt tecken på att man från samhällets sida inte accepterade deras levnadssätt och flyttvanor, kanske just för att kringresandet gjorde dem svåra för samhället att kontrollera. Det behöver dock inte betyda att resanderomer i praktiken blev mer utsatta för steriliseringar än andra diskriminerade och marginaliserade grupper. 


\section{Att minnas sin historia}

Den medicinska och rasbiologiska vetenskapen dominerade steriliseringslagens tillämpning. Dåtidens experter och tjänstemän, barnavårdsmän, fattigvårdsstyrelser, lärare, läkare och andra företrädare för kommunens sociala verksamhet, kunde förstå och försvara sin verksamhet med den kunskap som vetenskapssamhället ställt sig bakom. Det gjorde det möjligt för dem att distansera sig från de människor som pekades ut och som de anmälde för sterilisering.

Som nutida forskare har jag däremot svårt att se de människor som steriliserades med dåtidens distans, även om jag vet att en vetenskaplig undersökning också kräver en viss distans till det som ska utforskas och att just distansen har betydelse för val av metod och därmed för forskningsresultaten. När jag skrev min avhandling om steriliseringar i folkhemmet blev jag dock mycket upprörd över vad jag fann i arkiven. Jag ville, eller snarare, jag förmådde inte distansera mig från de berättelser som gällde de enskilda individer som jag hittade i källmaterialet. Därför valde jag att speciellt lyfta fram de omständigheter som med dagens ögon uppfattas som övergrepp mot samhällets allra mest utsatta individer. Mitt val har, kanske med rätta, fătt skarp kritik av historiker. Bland många idag levande steriliseringsoffer har min avhandling däremot hyllats. Detta är jag tacksam för. Trots detta, eller kanske just tack vare detta, vill jag avslutningsvis diskutera de svårigheter en historiker kan stöta på om hen väljer att stå fast vid de resultat som bygger på de uppgifter som finns bevarade i olika arkiv och med vetenskaplig distans förnekar individers eller gruppers minnen, upplevelser och erfarenheter.

Resanderomerna har många minnen av förföljelse och repression från myndigheternas sida, som dagens myndigheter och experter har tillägnat sig som grund för sin kunskap om resanderomernas villkor i samhället. Vissa av minnena av förföljelser går det att belägga i arkiven, medan motsatt förhållande gäller för andra berättelser. Den studie jag har redogjort för visar att resanderomernas berättelser om steriliseringar ligger väl i linje med hur dåtidens vetenskap och experter såg på dem som en grupp som borde komma i fråga för steriliseringar, samtidigt som jag hittills 
har hittat ytterst få belägg för att resanderomer var en speciellt utsatt grupp vad gäller de faktiskt genomförda steriliseringarna. Mina resultat kan på den här punkten jämföras med en norsk kollegas resultat beträffande lobotomeringar och steriliseringar av resanderomer i Norge. På Ris kyrkogård i Norge finns ett monument benämnt "Skammens sten". Det är en gemensam gravplats för patienter från sjukhuset Gaustad och stenen har sedan I960-talet stått som en symbol för övergrepp mot resandefolket, som lobotomi och steriliseringar. Historikern Per Haave, som har studerat de begravdas patientjournaler har dock kunnat konstatera att av de 55 personer som enligt arkiven ligger begravda under "Skammens sten" så tillhörde ingen av dem de resande och att ingen av dem var steriliserad och endast ett fătal av dem var lobotomerade. "Konklusjonen er at det ikke er knyttet en spesielt dramatisk historie til denne fellesgraven. Gravstedet har fått en sterk, symbolsk betydning, men resultatene av overgrepene knyttet til behandlingen på Gaustad er ikke å finne i denne graven”, enligt Per Haave. ${ }^{34}$ Enligt ordförande i "Taternes landsforening”, Holger Gustavsen, kommer dock föreningens medlemmar att fortsätta att hålla en minnestund vid graven varje år. Stenen får vara en symbol för övergrepp mot resandefolket: "Det er den eneste graven vi har. Hvis folket vårt ikke ligger der, hvor ligger de da? Det er fortsatt mange ubesvarte spørsmål som fortjener den hele og fulle sannhet. Uansett om det er tatere, jøder, kvener eller nordmenn som ligger der, så er det mennesker som ble lagt i en anonym grav og hemmeligholdt", sade Gustavsen i en intervju i Aftenposten. ${ }^{35}$

Berättelser och minnen, liksom vetenskapliga diskurser och experters uttalanden från den tid som minnena berör, pekar ibland åt ett annat håll än den information om den sociala praktiken som finns bevarad i arkiven. Detta konstaterande kan utgöra underlag för angelägna diskussioner dels om vad i vår historia som går att synliggöra med hjälp av de arkivsamlingar som finns och dels om villkoren för det kollektiva minnets konstituering.

\section{Noter}

I. Den mörka och okända historien: vitbok om övergrepp och kränkningar av romer under I90o-talet. Ds 20I4:8. 
2. Se t ex Socialstyrelsen (2006) Ombändertaganden av romska barn http/:socialstyrelsen.se. Romers rätt SOU 20I0:55 samt Rapporter utgivna av Delegationen för romska frågor 2007-2013.

3. Magnus Berg \& Jan Popp, Boken om Popp och hans mamma Alice: sjuttio års kamp för värdighet $i$ utkanten av Göteborg och Sverige (Göteborg 2014) s. 33.

4. Ibid s. 32 .

5. Se Zigenarinventeringen I944. Inreseförbudet gällde mellan I9I4 och I954. Definitionen av tattare och zigenare har redovisats i flertalet statliga utredningar. Se t.ex. Mattias Tydén, Från politik till praktik: de svenska steriliseringslagarna I935-I975 (Stockholm 2002) s. 62-63. Norma Montesino, Zigenarfrågan: intervention och romantik (Lund 2002) s. 95; Maria Ericson, Rapport angående en eventuell sanningskommission för romer och resande/resanderomer i Sverige, SOU 20I0:55 s. 8.

6. Norma Montesino, "Romer i svensk myndighetspolitik - ett historiskt perspektiv". Meddelanden från Socialhögskolan 20 I0:2 s. Iо.

7. Paulina de los Reyes "Ett olösligt problem, rapport om steriliseringslagarnas konsekvenser för romer och resande", i Vitboken: Ds 20I4:8., s. I9. Hon pekar särskilt ut 2002 års steriliseringsutredning.

8. Ibid. s. I9.

9. Christian Catomeris, Det obyggliga arvet. Sverige och främlingen genom tiderna, Stockholm 2004. Citerat i de los Reyes, s. I9-20.

IO. Vitboken Ds 2014:8.

I I. Vitboken Ds 20I4:8.

I2. Sociala Meddelanden I944, nr 2 s. I 6.

I3. Sociala Meddelanden I945, nr 5 s. 379.

I4. Nordiska Museet, Etnologiska undersökningen nr 78, svar på frågelista, akt nr U 23925 Bohuslän, Inlands nedre härad, Solberga och Järlanda socken. Upptecknare Karl G Larsson, Måljem Nol.

I 5. Socialstyrelsens tattarinventering I943, 5.e byrån H Io. Gunnar Dahlberg, "Antropologisk undersökning av tattare i Sverige”, 22 feb I944, Riksarkivet. 
I6. Ibid. s. 2 .

I7. Ibid. s. 4 .

I 8. Ibid. s. 8 .

I9. SOU I936:46, s. 65 .

20. Ibid.

2I. Maija Runcis, Steriliseringar i folkhemmet (Stockholm 1998) kapitel 6

22. Runcis (Stockholm I998) kapitel 9.

23. Mattias Tydén \& Ingvar Svanberg, "I nationalismens bakvatten" i Bryta, bygga, bo: svensk historia underifran, (red.), Gunnar Broberg, Ulla Wikander, Klas Åmark (Stockholm I 994) s. 23 I.

24. SOU I936:46 s. 27.

25. Ibid.

26. Sociala meddelanden, maj I 945 s. 375 .

27. Ibid. s. 380 .

28. Ibid.

29. I den offentliga statistiken anges I043 personer vara "tattare", men där endast 276 registerkort förekommer. Differensen mellan siffrorna säger något om hushållens storlek och familjer. För denna undersökning har endast 50 registerkort som rör kvinnor hunnits gå igenom. Arbetet fortsätter dock med en jämförelse av samtliga I 24 registrerade kvinnor i de fem redovisade länen.

30. Ibid. "Rasdrag" var en förtryckt fråga på registerkortet som hörde samman med frågan om levnadssätt”. Rasdrag var således inte ett uttryck som användes av anmälarna. Riksarkivet, Marieberg. Medicinalstyrelsens rättspsykiatriska nämnd. Diarier över inkomna ansökningar I94I. Dnr 2362, I94I (beslut ro november I94I).

3I. En syssloman är en månghundraårig gammal svensk titel som innebär ett juridiskt och ekonomiskt ansvar för annan person eller verksamhet. 
32. Socialstyrelsens "Tattarinventering” I943, registrerade kvinnor Göteborgs och Bohus Län. Socialstyrelsens tattarinventering I943, 5.e byrån H ıo. Riksarkivet.

33. Berg \& Popp (Göteborg 20I4) s. IO2.

34. Aftenposten 25 februari 2014.

35. Ibid. 